\title{
Twin Transplants; Twin Study Summary; Human Interest Topics
}

\author{
Nancy L. Segal \\ Department of Psychology, California State University, United States of America
}

\begin{abstract}
$\triangle \mathrm{n}$ overview of the nature and success of organ transplantation in monozygotic (MZ) twins is presented. Recent timely examples Ademonstrate the unique donor-recipient relationship shared by MZ co-twins. Next, a recent analysis of MZ co-twin differences in the epigenetic profile and associations with differences in life history factors is presented. This work has been the focus of considerable attention by scientists and the media. The final section of this column summarizes information and events concerning twins' longevity, screen careers, older parenting of twins and the origin of the word 'twin'.
\end{abstract}

\section{Twin Transplants}

One 1941 evening, in Fribourg, Switzerland, identical twin boys were born to one family and a single, nontwin boy was born to another family (McIndoe \& Franceschetti, 1949-1950). Shortly thereafter, unknown events caused the accidental 'switching' of one twin and the nontwin infant - as such, one twin boy and the singleton were raised as fraternal twins. The truth was eventually revealed when the children reached school age and all three boys were assigned to the same class at school. The obvious physical resemblance of the real identical twins raised the suspicion that they were actually the pair born 6 years earlier.

Blood tests and skin grafts were performed and confirmed that the two identical-looking boys were twins. (The use of skin grafts as a test for monozygotic [MZ] twinning was first performed in 1927. Skin grafts between individuals who are not $\mathrm{MZ}$ twins are unsuccessful. Interestingly, nine-banded armadillos, always born as sets of $\mathrm{MZ}$ quadruplets, have shown slow rejection of skin grafts. The possibility that armadillo co-quads have different histocompatibility antigens has been raised; see Anderson \& Benirschke, 1962. I also wonder if epigenetic differences might explain the rejections; see Twin Research Summary below.) The misplaced children were returned to their birth families, although some contact between the twins and the nontwin boy continued. As adults, both twins pursued professional careers, while the unrelated singleton became a postman (Scheinfeld, 1967).

\section{MZ Twins' Physical and Health Advantages}

The genetic identity of $\mathrm{MZ}$ twins gives them some unique medical advantages. One special feature is that they have an ideal donor-recipient relationship because of their identical immune systems. In the event that one identical twin experiences kidney failure, leukemia or certain cancers, organ donation and transplantation may be required. If so, then his or her identical co-twin is the best possible donor. In contrast, a nontwin individual often has difficulty identifying a suitable donor, especially if he or she has rare immune system characteristics.

The first recorded attempt at human kidney transplantation occurred in Russia in the 1930s, but was unsuccessful. Then, in 1954, medical history was made, given successful kidney transplantation between 23-year-old MZ male twins (Starzl, 1984). Organ donation between dizygotic (DZ) twins (who share $50 \%$ of their genes, on average) is less successful, although higher than that between more distant relatives. Transplantation between some DZ twins may actually be assisted by chimerism, the exchange of red blood cells during gestation — in fact, a 1959 medical report showed that skin grafted from a male twin to his female co-twin was successfully tolerated. It is also of interest that skin grafts between opposite-sex cattle twins, who have exchanged red blood cells in utero (freemartin effect), have been successful (Murray, 1992).

\section{Twin Stories}

Each successful transplant between identical twins (and each occasional failure) is a potential contribution to medical knowledge. Each operation also captures basic human themes of love and self-sacrifice. Several recent and revealing medical histories of twins - both MZ and DZ - are summarized below.

Identical twins Chris and Kevin Singleton from Parsippany Hills, New Jersey, played football in high school and at the University of Arizona, in Tuscon (Anderson, 1990; 'Extra Year Granted', 1990; Gola, 1990). Both twins were likely prospects for selection by the National Football League. Then, in 1989, Kevin was diagnosed with leukemia. He received a bone marrow transplant in which his twin brother, Chris, was the donor. The twins' physician, Dr. Robert Rifkin at the

Address for correspondence: Nancy L. Segal, Department of Psychology, California State University, Fullerton, CA 92834, USA. Email: nsegal@fullerton.edu 
Arizona Cancer Center, and coach, Dick Tomey, observed that the twins' relationship was a key factor in their ability to cope with Kevin's illness, and that the transplant may have strengthened their relationship. By 1990, Kevin's leukemia had gone into remission. He continued to practice football, and was given a 6th year of eligibility. In 1995 Kevin was an assistant football coach for the Arizona Wildcats, the year his twin brother Chris was inducted into the Arizona Sports Hall of Fame. Chris, who played football for the Miami Dolphins, was in Cincinnati for a game against the Bengals. Kevin graciously accepted the award on behalf of his brother (Dregal, 1995).

Opposite-sex twins Alison and Tyler were born in Indianapolis, Indiana in April, 1990. Alison was born with a fatal heart deformity, while her twin brother suffered from brain death due to intrauterine asphyxiation prior to birth. When it was determined that the twins matched on critical compatibility factors, a decision was made to transplant Tyler's heart into Alison. The operation was successful, although drug therapy was needed to suppress possible rejection reactions. Alison was identified as the 'youngest and tiniest newborn to undergo such a procedure' (see Segal, 1991).

Two-week-old twins Nathaniel and Nicholas are currently facing different problems. Both infant boys were born with a rare condition called dilated cardiomyopathy in which the heart muscles are too weak to pump blood (Reitman, 2005). It is estimated that they will only live 1 year if suitable organ donors (babies who die soon after birth) are not found. The twins' situation is complicated by the long waiting list and the fact that they have rare $\mathrm{O}$ negative type blood. The twins are now under the care of physicians at University of California, Los Angeles (UCLA). Their pediatric surgeons say that if two hearts were found, it would allow them to perform the first ever heart transplant operation on newborn twins. (Note: it is unclear if the twins are $\mathrm{MZ}$ or DZ.)

In June 2005, a spectacular twin transplant was announced: a 24-yearold identical female twin who suffered from ovarian failure received healthy ovarian tissue donated by her twin sister (Grady, 2005; Silber et al., 2005). Her cycles resumed within 3 months. She conceived during her second cycle and delivered a healthy female infant after a 38-week pregnancy. The source of her infertility is unknown - her medical history shows that she stopped menstruating at the age of 14 years, after which her ovaries and uterus shrunk like those of a woman undergoing menopause.

The physicians associated with this case were initially surprised to find a set of identical twins discordant for fertility. They have, however, identified other such pairs since then and have performed additional ovarian transplant operations. Their work will, no doubt, be encouraging to women undergoing chemotherapy for cancer, a procedure damaging to the ovaries. These women could have their ovarian tissue removed and preserved prior to chemotherapy, and later transplanted back in order to conceive. The surgeons also discovered some troubling news during the course of their work - they found that infertility is five times higher among twins than nontwins. Reasons for this are unclear, but efforts to confirm this figure and to find out why are important.

The last story under review parallels the previous one, except that it concerns MZ males. It was reported in the late 1970 s by the same principal investigator, but appears to be less well known (Silber, 1978). It is, however, equally compelling. A male twin was born without testicles, a condition called anorchia, while his twin brother was normal. At the age of 30 , the twin with two testes donated one testis for transplantation into his brother. The anorchic twin's serum testosterone levels normalized 2 hours after surgery, and his FSH (follicle stimulating hormone) and LH (lutenizing hormone) levels were within normal limits after 4 weeks. He was able to have an active sex life and eventually conceived a child, once his spouse's menstrual cycle difficulties were resolved (Silber, 1980).

\section{Implications}

The willingness of the twins to donate organs to their co-twin reveals a great deal about the closeness of their social relationship. I am unaware of any published studies comparing $\mathrm{MZ}$ and DZ twins' feelings about donating organs to one another (I have some relevant, albeit unanalyzed, data), but such efforts would be informative. One could test the prediction that $\mathrm{MZ}$ twins would be somewhat more willing to comply and that decisions would be rendered more spontaneously. This outcome would be consistent with studies showing closer social relations and cooperation between $\mathrm{MZ}$ than $\mathrm{DZ}$ twins (Segal, 2000).

Even while identical twins and other close relatives may be preferred organ donors for family members in need, this does not obligate them to donate their organs. It was alarming to read a comment by Fefer, Cheever and Greenberg (1986) in a paper reporting favorable outcomes from bone marrow transplants performed on $130 \mathrm{MZ}$ twins: 'Thus for twins with hematologic cancers the question is not whether to perform a transplant but when to do so' (p. 1272). This statement raises unique legal themes. Could a twin bring legal action against an MZ co-twin if he or she did not wish to donate an organ? Could a twin justify common ownership of blood or organs based on genetic identity? (see Segal, 2000). I have not heard of any such cases, but they are not impossible to imagine. 


\section{Twin Study Summary}

\section{Epigenesis: MZ Twin Differences and Their Implication}

There has been considerable attention surrounding a paper published recently in the Proceedings of the National Academy of Science USA. Coincidentally, this paper appeared just as the 2005 mid-Congress meeting of the International Society of Twin Studies and annual meeting of the Behavior Genetics Association were underway. The paper, which focused on the within-pair epigenetic profiles of $40 \mathrm{MZ}$ twin pairs, represented the efforts of an international interdisciplinary team (Fraga et al., 2005). The paper's publication was followed by reports, analysis and commentary in newspaper columns worldwide (Wade, 2005; Weiss, 2005). The material summarized below has been drawn from these sources.

Why has this study attracted so much attention? It has done so because $M Z$ twins differing in selected traits are the best research participants for discovering why some people develop cancer while others do not, or why some people become schizophrenic, while others do not - even if they have a genetically-based susceptibility. Specifically, MZ twins discordant for particular traits become naturally occurring co-twin control cases, allowing researchers to consider the range of environmental effects that may trigger genetic expression in one twin, but not in the other.

Every student in biology and genetics will recall learning about epigenesis - the chemical changes that occur in each person's genes throughout development that affect the expression of those genes. The changes include DNA methylation and histone acetylation. DNA methylation involves the addition of methyl groups to DNA, causing deactivation of the gene(s). Histone acetylation involves the addition of acetyl groups to histone proteins, leading to activation of a nonactive gene(s). It is suspected that events in each person's environment for example, chemical exposure, life stress, dietary habits - may underlie epigenetic changes. Another possibility is that 'epigenetic marks' (which are identical in identical twins at birth) are eliminated at random over the life course. These processes could explain why $M Z$ twins, who originate from a single fertilized egg and share identical genes, are not quite identical in all measured behavioral and physical traits.

The twin sample included 80 Caucasian MZ twins from 40 pairs living in Spain. They comprised 15 male sets and 25 female sets, and ranged in age from 3 to 74 years, with a mean age of 30.6 years. Some pairs were monochorionic and others were dichorionic, although we do not know the relative distribution of these two placental types. The monozygosity of the pairs was established by comparative examination of DNA markers.

In addition to within-pair analyses of DNA methylation and histone acetylation, twin participants completed questionnaires concerning their medical life history, dietary practices, physical activities and use of alcohol, tobacco and pharmacological agents.
Researchers also measured their heights and weights. Finally, twins were questioned about genetic conditions and characteristics among their family members. This information was used to estimate the degree of phenotypic difference between co-twins.

The key finding from the study was that very young twins do not differ epigenetically, but older twins do show some marked differences in the content and distribution of 5-methylcytosine DNA and histone acetylation. Additionally, twins who spent fewer years together and/or showed greater differences in their health histories showed the greatest differences in their epigenetic profile. The authors pointed out that small epigenetic differences can translate into large phenotypic differences between co-twins. Most importantly, this new set of findings gives researchers a fresh understanding of how genetically identical twins can diverge in selected behavioral and physical traits. No longer will explanations of identical co-twin differences simply be 'the environment' - now there is a new fruitful (and specific) research path to pursue.

This paper is an exciting read. At the same time, it is important to recall that identical twins are more alike than any other pair of people. That they maintain this resemblance in many, if not in all, measured traits underlines the significance of genetic effects on human development. Epigenetic twin studies that are prospective and longitudinal in design are, hopefully, being planned.

\section{Human Interest Topics}

\section{Long Life}

I was impressed by news of identical twin sisters who come from 'the land of 10,000 stories' (Huppert, 2005). The twins have kept the same 9 a.m. hair salon appointment for the last 34 years. They have always purchased identical outfits - if stores carry just one coat or one dress in their size they refuse to buy it. Interestingly, only one twin needs eyeglasses (her sister has had surgery) — nevertheless, the twin with the improved eyesight continues to wears eyeglasses to maintain the pair's identical appearance.

The twins in question are Doris Hines and Dorothy Seifert, of Ellsworth, Wisconsin. They are 88 years old. There is, however, a curious difference between them: Doris has 13 children, while Dorothy has only one. Today Doris is the proud grandmother of 103 grandchildren and great grandchildren. But each twin feels as though she has raised
14 children. This is not surprising - it has been shown that MZ twins express greater closeness and greater perceived similarity with their nieces and nephews (their genetic children) than DZ twins (Segal, 2005; Segal et al, 2005).

\section{Screen Careers}

It is likely that few people have heard of identical twins Naomi and Ruth Stevenson, other than their friends and family members in their hometown of 
Tuscon, Arizona. But many people will have heard of the Brewster twins, Gloria and Barbara. After they were spotted at a fair, the sisters enjoyed brief screen careers in the 1930s and 1940s ('Passings: Barbara LeMond', 2005; Williams, 2005). They were contracted by 20th Century Fox and called 'the most beautiful twins in America'. Their nine film roles included pictures such as Little Miss Broadway and Hold That Coed. Both twins appeared in a 1940 comedy called Twincuplets with another set of twins, Claude and Clarence Stroud. Gloria Brewster and Claude Stroud eventually married, an event that ended Gloria's acting career. Still, the sisters were always very close and visited each other often.

Barbara went on to perform live on the New York stage, and performed in United Service Organization (USO) shows in the South Pacific during World War II. She passed away in June 2005, about 10 years after her twin sister, Gloria.

\section{Mother of Twins}

I was intrigued by the following news headline: 'Alabama: A Mother Again at 57, She Felt Like Dancing' (2005). Reese Swain, a mother of two grown children and a 6-year-old son, recently delivered DZ twins Christian and Diana. Reasoning that she did not want her young son to grow up as an only child, she decided to become pregnant once again. She accomplished this via in-vitro fertilization, a procedure that has a well-known risk of twinning.

The twins, born on April 20, were 4 weeks premature. The delivery went so smoothly that Swain danced with her spouse shortly thereafter. Such a positive outcome is likely to be very encouraging to prospective older mothers. However, it is important to bear in mind that multiple births can pose serious physical risks to mothers and babies. Consequently, reproductive specialists are currently improving technologies to increase the chances of successful conception and delivery of single infants.

\section{Origins of the Word 'Twin'}

The July 4 entry in the Word Origin Calendar (2005) provides a definition for the word twist - it refers to 'an action or object that winds'. It also provides the definition for the root prefix twi - in Old English, this means 'two' and refers to the concept of splitting something into two parts. The final section of the entry reads, "Ultimately, the same root influenced yet another modern English term involving doubling, the word "twin".'

\section{References}

Alabama: A mother again at 57, she felt like dancing. (2005, May 27). New York Times (Associated Press), p. A-17.

Anderson, D. (1990, April 22). The bonemarrow transplant twins. New York Times.

Anderson, J. M., \& Benirschke, K. (1962). Tissue transplantation in the ninebanded armadillo, Dasypus novemcinctus. Annals of the New York Academy of Sciences, 99, 399-414.

Dregal, C. (1995). UA Hall of Fame's new inductee list includes Lofton, Gomez. Retrieved July, 2005, from http:// wildcat.arizona.edu//papers/oldwildcats/fall95/October/October3, 1995/07_3_m.htmlhttp://wildcat. arizona.edu/papers/oldwildcats/fall95/O ctober/October3,1995/07_3_m.html.

Extra year granted. (1990, August 9). New York Times.

Fefer, A., Cheever, M. A., \& Greenberg, P. D. (1986). Identical-twin (syngeneic) marrow transplantation for hematologic cancers. Journal of the National Cancer Institute, 76, 1269-1273.

Fraga, M. F., Ballestar, E., Paz, M. F., Ropero, S., Setien, F., Ballestar, M. L., Heine-Suner, D., Cigudosa, J. C., Urioste, M., Benitez, J., Boix-Chornet, M., Sanchez-Aguilera, A., Ling, C., Carlsson, E., Poulsen, P., Vaag, A., Stephan, Z., Spector, T. D., Wu, Y. Z., Plass, C., \& Esteller, M. (2005). Epigenetic differences arise during the lifetime of monozygotic twins. Proceedings of the National Academy of Sciences USA, 102, 10604-10609.

Gola, H. (1990, April 17). Arizona LB lives dream for twin. New York Post, p. 43.

Grady, D. (2005, June 8). Woman has child after receiving twin's ovarian tissue. New York Times, p. A12.

Huppert, B. (2005). The land of 10,000 stories: Special twins. KARE News Extra. Retrieved July 8, 2005, from http:// www.kare11.com/extras/stories.aspx

McIndoe, A., \& Franceschetti, A. (1949-1950). Reciprocal skin homografts in a medico-legal case of familial identification of exchanged identical twins. British Journal of Plastic Surgery, 2, 283-289.
Murray, J. E. (1992). Human organ transplantation: Background and consequences. Science, 256, 1411-1415.

Passings: Barbara LeMond, 87, Performed with sister as the Brewster Twins. (2005, June 25) Los Angeles Times, p. B13.

Reitman, V. (2005, July 20). Facing a short supply of small hearts. Los Angeles Times, p. B1, B6.

Scheinfeld, A. (1967). Twins and supertwins. Baltimore, MD: Penguin Books.

Segal, N. L. (1991). Giving the gifts of life. Twins Magazine, 7, 50-52.

Segal, N. L. (2000). Entwined lives: Twins and what they tell us about human behavior. New York: Plume.

Segal, N.L. (2005). Indivisible by twins: Lives of extraordinary twins. Cambridge, MA: Harvard University Press.

Segal, N. L., Seghers, J., Castillo, R., Vanevery, A., \& Moreno, T. (2005, June). Social closeness of $M Z$ and $D Z$ twin parents toward their nieces and nephews. Paper presented at the meeting of the 17th Human Behavior and Evolution Society, Austin, TX., June $1-5,2005$.

Silber, S. J., (1978). Transplantation of a human testis for anorchia. Fertility and Sterility, 30, 181-187.

Silber, S. J. (1980). Pregnancy after testicular transplant: Importance of treating the couple. Fertility and Sterility, 33, 454-457.

Silber, S. J., Lenahan, K. M., Levine, D. J., Pineda, J. A., Gorman, K. S., Friez, M. J., Crawford, E. C., \& Gosden, R. G., (2005). Ovarian transplantation between monozygotic twins discordant for premature ovarian failure. New England Journal of Medicine, 353, 58-63.

Starzl, T. E. (1984). The landmark identical twin case. Journal of the American Medical Association, 251, 2572-2573.

Wade, N. (2005, July 5). Explaining differences in twins. New York Times, p. F5.

Weiss, R. (2005, July 5). Twin data highlight genetic changes: Minor differences increase with age. Washington Post, p. A2. Available at http://www. washingtonpost.com/wp-dyn/ content/article/2005/07/04/AR200507 0400845.html

Williams, J. (2005, June 30). Barbara Lemond, of Brewster Twins. The San Diego Union-Tribune. Retrieved July, 2005, from http://www.signonsandiego.com/uniontrib/20050630/ne ws_1m30lemond.html

Word Origin Calendar 2005. (2004). Denver, CO: Accord. 